\title{
Polyreactive Autoantibodies Purified from Human Intravenous Immunoglobulins Prevent the Development of Experimental Autoimmune Diseases
}

\author{
Martine Bruley-Rosset, Luc Mouthon, Youri Chanseaud, Frédéric Dhainaut, \\ Jacky Lirochon, and Dominique Bourel \\ Laboratoire Français du Fractionnement et des Biotechnologies (MBR, FD, JL, DB), Les Ulis, and INSERM E 209 \\ (MBR), Hopital St-Antoine, Paris, and UPRES EA 3408 (LM, YC), Formation Associée Claude Bernard, UFR-SMBH \\ Léonard de Vinci, and Internal Medicine Unit (LM), Hôpital Avicenne, Assistance Publique-Hôpitaux de Paris, \\ Bobigny, France
}

\begin{abstract}
SUMMARY: Intravenous immunoglobulins (IVlg) are therapeutic preparations of normal human polyclonal $\lg G$ (IgG) that exert immunomodulatory effects in patients with autoimmune or systemic inflammatory diseases. Two different lgG subfractions were evaluated for their respective immunomodulatory effects in the treatment of experimental autoimmune diseases: a fraction enriched in antibodies that recognize the $F\left(a^{\prime}\right)_{2}$ portion of IVIg and a fraction of natural polyreactive autoantibodies purified on a dinitrophenyl (DNP)-Affiprep immunoadsorbent. A very small fraction of IgG interacting with DNP but not with F(ab') ${ }_{2}$ fragments expressed an increased ability to bind to self-antigens. The anti-DNP fraction, but not the anti-idiotype fraction, protected against inflammation observed in collagen-induced arthritis and experimental autoimmune encephalomyelitis in rats. Furthermore, it was able to reduce the occurrence of spontaneous diabetes mellitus in nonobese diabetic mice at lower concentrations than unfractionated IVIg. The therapeutic benefit of the anti-DNP fraction was associated with the inhibition of secretion of proinflammatory cytokines and stimulation of secretion of IL-1 receptor antagonist. Our results provide evidence that polyreactive autoantibodies play a role in the protective effect of IVIg in experimental models of autoimmune diseases in which inflammatory reactions are part of the disease process. (Lab Invest 2003, 83:1013-1023).
\end{abstract}

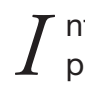
ntravenous immunoglobulins (IVlg) are therapeutic preparations of normal human polyclonal lg $\mathrm{G}$ (IgG) that are obtained from pools of plasma from a large number of healthy blood donors. IVIg contain immune antibodies directed toward external antigens and natural autoantibodies that recognize intracellular, cell-surface, and circulating antigens, as well as $\mathrm{V}$ regions of antibodies (idiotypes) (Kazatchkine et al, 1994). Natural autoantibodies are produced without deliberate immunization (Coutinho et al, 1995) and are thought to be generated by positively selected autoreactive B cells (Hayakawa et al, 1999). They are polyreactive and express variable affinity for selfantigens (Berneman et al, 1992; Lacroix-Desmazes et al, 1998). In addition, almost all human and murine natural $\mathrm{m}$-antibodies tested thus far react with a large panel of ligands, including the dinitrophenyl (DNP) hapten (Berneman et al, 1992; Dighiero et al, 1983; Seigneurin et al, 1988).

\section{DOI: 10.1097/01.LAB.0000077982.70800.02}

Received January 31, 2003.

Youri Chanseaud is a recipient of a grant from the French Ministry of Research. This work was supported by INSERM (CreS No. 4CRO8F).

Address reprint requests to: Dr. M. Bruley-Rosset, INSERM E 209, Bâtiment Kourislky, Hopital St. Antoine, 184 rue du Faubourg St. Antoine, 75012 Paris, France.E-mail: rosset@st.antoine.inserm.fr
Originally used as a substitutive therapy for primary antibody deficiencies, IVIg has more recently been proven to be beneficial in autoimmune and systemic inflammatory diseases (Dalakas, 1997; Dwyer, 1992; Kazatchkine and Kaveri, 2001). The mechanisms behind the immunomodulating effects of IVIg are now better understood and implicate both $\mathrm{Fc}$ and $\mathrm{V}$ regions of infused IgG (Larroche et al, 2002). IVIg interact with complement components and with Fc receptors on the surface of phagocytes (Larroche et al, 2002). In an experimental model of idiopathic thrombocytopenic purpura, IVIg were recently shown to prevent platelet destruction mediated by pathogenic autoantibodies by inducing expression of the inhibitory receptor Fc $\gamma$ RIIB on splenic macrophages (Samuelsson et al, 2001). Moreover, by blocking Fc receptors of the neonate ( $F c R n)$ that enable IgG to enter the cells by pinocytosis and thereby protect them against catabolism, IVIg could be responsible for the accelerated rate of IgG catabolism in patients with antibodymediated autoimmune disorders ( $\mathrm{Yu}$ and Lennon, 1999). IVIg also modulate cytokine production as well as cell activation and proliferation (van Schaik et al, 1992) through the recognition of a large number of cell-surface molecules, such as $\mathrm{V}$ regions of $\mathrm{B}$ - and T-cell receptors, CD4, CD5, HLA class-I molecules, Fas, and Arg-Gly-Asp (RGD) sequence that is part of many adhesive extracellular-matrix proteins (Dalakas, 


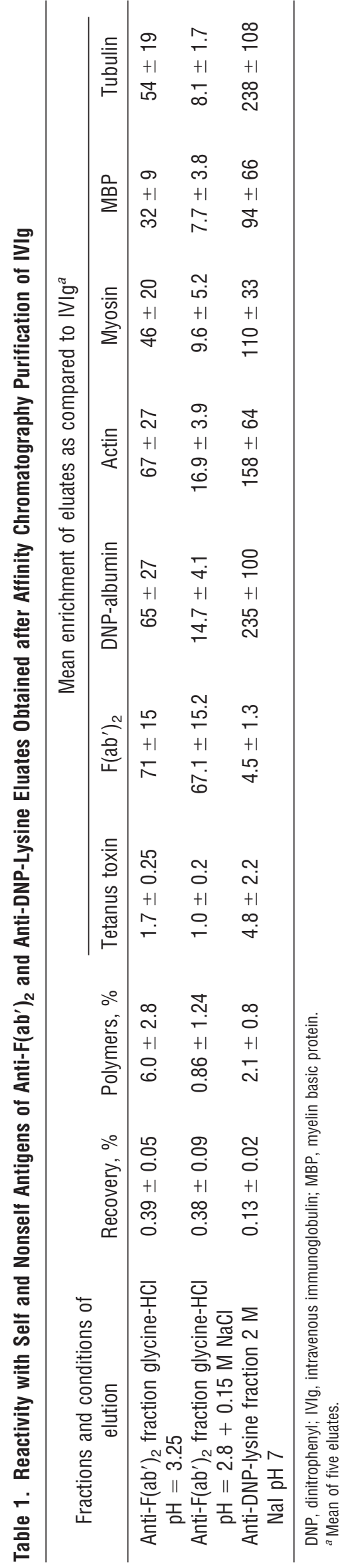

1997; Dwyer, 1992; Kazatchkine and Kaveri, 2001; Larroche et al, 2002; Rhoades et al, 2000). IVlg may also neutralize circulating autoantibodies and modulate T- (Marchalonis et al, 1993) and B-cell repertoires (Hayakawa et al, 1999) through $\mathrm{V}$ region-dependent interactions.

IVlg contain anti-idiotype antibodies that are able to interact with natural and disease-associated autoantibodies (Kaveri et al, 1993; Rossi et al, 1991). A fraction of IVIg containing anti-idiotype antibodies was previously obtained by affinity purification of $F\left(a b^{\prime}\right)_{2}$ fragments of IVIg onto Sepharose-bound $F\left(a b{ }^{\prime}\right)_{2}$ fragments of IVIg prepared from the same source (Dietrich et al, 1993). A greater proportion of autoantibodies and complementary (anti-idiotype) antibodies to autoantibodies were observed in this fraction compared with intact IVIg (Dietrich et al, 1993). It was thus thought to be potentially more effective than IVIg for the therapeutic control of autoimmune diseases. Polyreactive autoantibodies can also be obtained by affinity purification of normal human IgG using a DNPSepharose column (Berneman et al, 1993). To discriminate between immunomodulating effects due to polyreactive autoantibodies or anti-idiotype antibodies, we isolated and characterized the immunomodulatory properties of an anti- $\mathrm{F}\left(\mathrm{ab} \mathrm{b}^{\prime}\right)_{2}$ fraction (antiidiotype autoantibodies) and an anti-DNP fraction (natural polyreactive autoantibodies). We observed that the anti-DNP IgG fraction, which represent a very small portion of IVIg, expressed increased ability to bind to self-antigens and protected against inflammation associated with several experimental autoimmune diseases, whereas the same effect was not observed with the anti- $F\left(a b^{\prime}\right)_{2}$ fraction. Therapeutic effect of the anti-DNP fraction was associated with inhibition of secretion of proinflammatory cytokines and stimulation of secretion of the anti-inflammatory cytokine IL-1 receptor antagonist (IL-1ra).

\section{Results}

Preparation and Reactivity of an Anti-F(ab') $)_{2}$-Enriched Fraction from IVIg

IVlg were affinity purified on an IVIg-coupled $\mathrm{N}$-hydroxysuccinimide (NHS) Affigel column, and elution was performed with glycine- $\mathrm{HCl}$ at $\mathrm{pH} 3.25$. The mean reactivity of five eluates is presented in Table 1. The amount of IgG retained was $0.39 \%$, and the level of antibody enrichment for $F\left(a b{ }^{\prime}\right)_{2}$ fragments was 71 . This fraction was $32-$ to 67 -fold more reactive than intact IVIg for all autoantigen sources tested. In contrast, reactivity with the tetanus toxoid (TT) was not enriched at all. Molecular weight analysis by high pressure liquid chromatography revealed the presence of a significant percentage of polymers $(6 \%)$ that was not present in unfractionated IgG $(<1 \%)$. To decrease the amount of polymers, $0.15 \mathrm{M} \mathrm{NaCl}$ was added during the elution with glycine- $\mathrm{HCl}$ performed at $\mathrm{pH} 2.8$; the amount of polymers was thus reduced to $0.86 \%$, while the level of $F\left(a b^{\prime}\right)_{2}$ enrichment was not modified (67.1). Surprisingly, however, a 4-fold reduc- 
tion in the reactivity with DNP, actin, myosin, myelin basic protein (MBP), and tubulin was observed. The fraction containing a low percentage of polymers is referred to as the "anti-F(ab') ${ }_{2}$ fraction" and was used for in vitro and in vivo functional studies.

\section{Preparation and Reactivity of Anti-DNP-Lysine IgG Fraction from IVIg}

Experiments were performed with a column of DNPlysine coupled NHS-Affiprep, and elution of bound IVIg was performed with $2 \mathrm{M} \mathrm{Nal} \mathrm{pH}$ 7.0. This agent was selected instead of glycine- $\mathrm{HCl}$ because of its higher chaotropic activity, which allowed elution to take place at neutral $\mathrm{pH}$. In these conditions we obtained a low level of polymers (2.1\%). We observed that a small amount of the loaded unfractionated IVIg was retained $(0.13 \%)$ and that the eluted fraction was enriched 235-fold in anti-DNP activity and expressed strong reactivity with autoantigens $(\times 94$ to $\times 238)$ but not with $F\left(a b^{\prime}\right)_{2}$ fragments of IVIg or the TT (Table 1). The eluate is referred to as the "anti-DNP-fraction."

Unfractionated IVIg, anti-F(ab') $)_{2}$, and anti-DNP fractions obtained from IVIg tested at an IgG concentration of $200 \mu \mathrm{g} / \mathrm{ml}$ recognized more than 20 protein bands in normal human liver and muscle tissue extracts as assessed by quantitative immunoblotting. However, some of the immunoreactivity peaks were higher in the case of the anti-DNP fraction than observed in the case of unfractionated IVIg or anti$\left.\mathrm{F}(\mathrm{ab})_{2}\right)_{2}$ fraction (data not shown).

Taken together, these findings clearly demonstrated that the anti-F(ab') $)_{2}$ and anti-DNP fractions did not express the same antibody repertoires.

\section{Collagen-Induced Arthritis (CIA) in Rats}

Injection of 250 to $350 \mu \mathrm{g} / \mathrm{kg}$ of collagen resulted in the development of arthritis in $80 \%$ to $90 \%$ of Lewis rats. Preliminary experiments (data not shown) demonstrated that ip injection of $500 \mathrm{mg} / \mathrm{kg}$ of IVlg protected against CIA with the same efficacy either by ip or iv route. A dose of $50 \mathrm{mg} / \mathrm{kg}$ of IVlg did not reduce arthritis severity but significantly delayed disease onset (Fig. 1, A to C). No effect was observed at $5 \mathrm{mg} / \mathrm{kg}$ and $0.5 \mathrm{mg} / \mathrm{kg} \mathrm{IVIg} \mathrm{(Fig.} \mathrm{1A).} \mathrm{Administration} \mathrm{of} 500$ $\mathrm{mg} / \mathrm{kg}$ of human serum albumin (HSA) ip had no effect on disease development (data not shown).

The anti- $\left.\mathrm{F}(\mathrm{ab})_{2}\right)_{2}$ fraction at $50 \mathrm{mg} / \mathrm{kg}$ protected against the disease significantly $(p<0.05)$ as compared with the untreated group but not better than 50 $\mathrm{mg} / \mathrm{kg}$ IVlg (Fig. 2B). The dose of $5 \mathrm{mg} / \mathrm{kg}$ of anti$\mathrm{F}(\mathrm{ab})_{2}$ fraction was as inefficient as IVIg (Fig. 1, A and $B)$. However, in the group that received the anti-DNP fraction, the disease severity was significantly reduced either at $50 \mathrm{mg} / \mathrm{kg}(p<0.01)$ or $5 \mathrm{mg} / \mathrm{kg}(p<0.05)$ as compared with the control group (Fig. 1C). The protection obtained with the anti-DNP fraction was significantly better than that observed with $50 \mathrm{mg} / \mathrm{kg}$ IVIg. The results indicated that the anti-DNP fraction provided better protection than intact IVIg or the anti$\mathrm{F}(\mathrm{ab})_{2}$ fraction.

\section{Experimental Autoimmune Encephalomyelitis (EAE) in Rats}

No therapeutic effect was observed when unfractionated IVIg or the anti-DNP fraction were injected ip from Day 0 to Day 8 at $500 \mathrm{mg} / \mathrm{kg}$ and $50 \mathrm{mg} / \mathrm{kg}$, respec-

\section{A. Effect of IVIG}
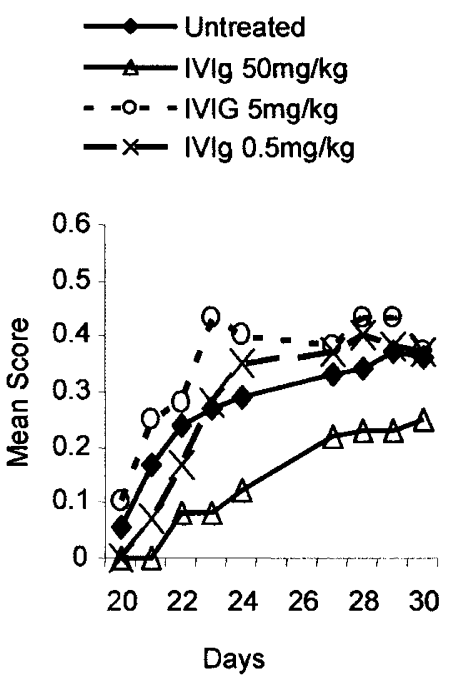

\section{B. Effect of Anti-F(ab')2 Fraction}
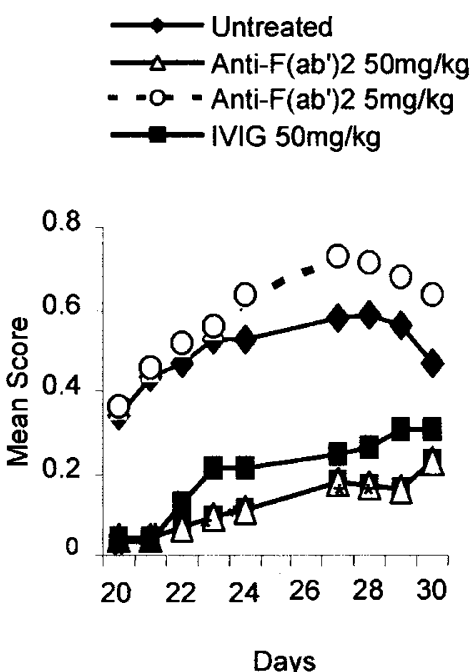

\section{Effect of Anti-DNP Fraction}
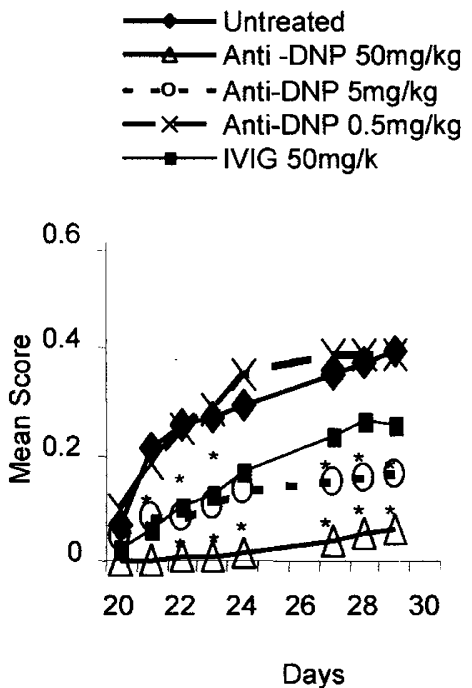

Figure 1.

Antidinitrophenyl fraction protected better than anti- $\mathrm{F}\left(\mathrm{ab}{ }^{\prime}\right)_{2}$ fraction and intravenous immunoglobulin (IVIg) against collagen-induced arthritis. Dark-Agouti rats were immunized with collagen, and the mean arthritic score was measured. (A) Mean arthritic score of 12 animals either left untreated or treated ip from Day 0 to Day 3 with four injections of IVIg at doses of 50,5 , or $0.5 \mathrm{mg} / \mathrm{kg}$. (B) Mean arthritic score of six to eight animals either left untreated or treated from Day 0 to Day 3 ip with four injections of anti-F(ab') ${ }_{2}$ fraction at the doses of 50 or $5 \mathrm{mg} / \mathrm{kg}$ or of IVIg at the dose of $50 \mathrm{mg} / \mathrm{kg}$. (C) Mean arthritic score of 12 animals either left untreated or treated ip from Day 0 to Day 3 with four injections of anti-DNP fraction at the doses of 50,5 , or $0.5 \mathrm{mg} / \mathrm{kg}$ or of IVIg at the dose of $50 \mathrm{mg} / \mathrm{kg}$. Significant $(p<0.05)$ compared with the untreated group using Student's $t$ test. 
A. Intraperitoneal injection of IgG
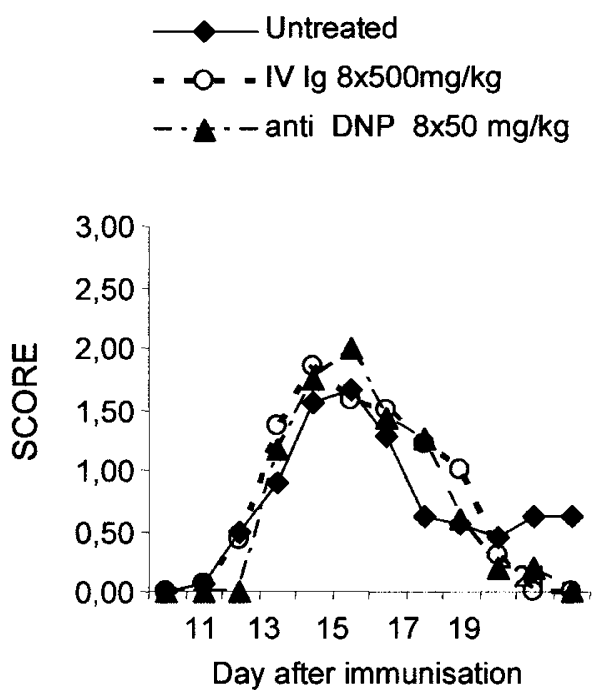

B. Intrathecal injection of IgG

$$
\begin{aligned}
& - \text { untreated } \\
& -\curvearrowleft-\text { IV Ig } 8 \times 100 \mathrm{mg} / \mathrm{kg} \\
& -\infty-\text { - IV Ig } 8 \times 25 \mathrm{mg} / \mathrm{kg} \\
& --\Delta-\text { - Anti DNP } 8 \times 25 \mathrm{mg} / \mathrm{kg}
\end{aligned}
$$

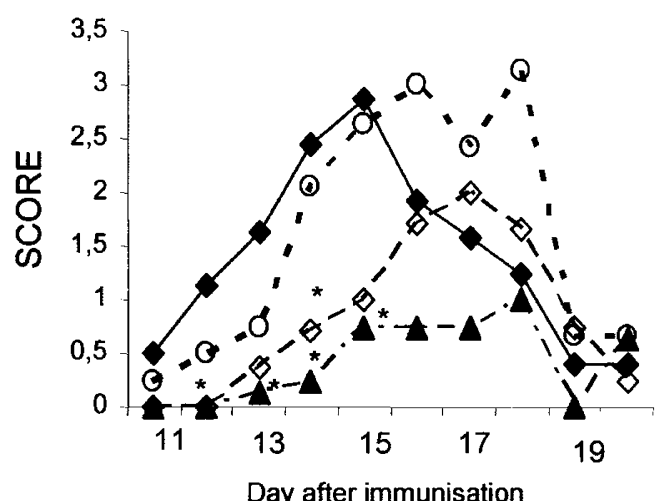

Figure 2.

Anti-dinitrophenyl (DNP) fraction protected better than intravenous immunoglobulin (IVIg) against experimental autoimmune encephalomyelitis (EAE) when injected intrathecally. Female Lewis rats were immunized with $1 \mu \mathrm{g}$ of myelin basic protein, and the EAE score was measured. (A) Mean score of eight animals either left untreated or treated ip from Day 0 to Day 7 with eight injections of IVIg at the dose of $500 \mathrm{mg} / \mathrm{kg}$ or of the anti-DNP fraction at the dose of $50 \mathrm{mg} / \mathrm{kg}$. (B) Mean score of eight animals either left untreated or treated intrathecally from Day 0 to Day 7 with eight injections of IVIg at the doses of 100 or 25 mg/kg or of the anti-DNP fraction at the dose of $25 \mathrm{mg} / \mathrm{kg}$. Significant $(p<0.05)$ compared with the untreated group using Student's $t$ test.

tively (Fig. 2A). In a subsequent experiment, $50 \mu \mathrm{l}$ of IVIg and the anti-DNP fraction were injected intrathecally. The dose of $25 \mathrm{mg} / \mathrm{kg}$ of the anti-DNP fraction significantly inhibited $(p<0.05)$ the disease compared with untreated mice, whereas only a delay in symptoms was observed with intact IVIg at a dose of 100 $\mathrm{mg} / \mathrm{kg}$ but not of $25 \mathrm{mg} / \mathrm{kg}$ (Fig. 2B).

\section{Type I Diabetes Mellitus in Non-obese Diabetic (NOD) Mice}

The effect of IgG given at birth was monitored in female NOD mice on the spontaneous development of diabetes; in male NOD mice, because only $20 \%$ of mice displayed diabetic symptoms, cyclophosphamide (CYC) was administered to promote the onset of disease by abrogating suppressor mechanism (Andersson et al, 1991).

\section{CYC-Induced Diabetes in Male NOD Mice}

Male mice were injected ip with CYC twice at 8 and 10 weeks of age. Fifty percent of untreated or $60 \%$ of HSA-treated NOD mice developed diabetes mellitus (Fig. 3A). Early treatment with $1 \mathrm{mg}$ IVIg or $0.1 \mathrm{mg}$ of the anti-DNP fraction significantly reduced the incidence of diabetes mellitus to $17 \%(p=0.0002)$ and $21 \%(p=0.009)$, respectively. In contrast, $0.1 \mathrm{mg}$ of the anti- $F\left(a b{ }^{\prime}\right)_{2}$ fraction did not significantly reduce the incidence of diabetes mellitus $(43 \%, p=0.10)$.

\section{Spontaneous Development of Diabetes Mellitus in Female NOD Mice}

Seventy-two percent of untreated female NOD mice were diabetic at 40 weeks of age (Fig. 3B), whereas only $43 \%(p=0.014)$ and $37 \%(p=0.004)$ were diabetic after IVIg $(1 \mathrm{mg})$ or anti-DNP fraction $(0.1 \mathrm{mg})$ treatment, respectively. The anti- $F(a b ')_{2}$ fraction $(0.1$ $\mathrm{mg}$ ) did not protect from the occurrence of diabetes mellitus because $60 \%$ of mice were diabetic $(p=$ 0.49). Surprisingly, HSA significantly reduced the incidence of the disease $(p<0.013)$ as well as IVIg.

\section{Influence of IVIg and Anti-DNP and Anti-F(ab') ${ }_{2}$ Fractions on the Proliferation and Cytokine Secretion Occurring During Mixed Lymphocyte Culture (MLC)}

Human peripheral blood mononuclear cell (PBMC) proliferation in MLC was reduced in a dose-dependent fashion in IVIg containing cultures as assessed by thymidine incorporation (Fig. 4). The inhibition was greater in the presence of the two fractions, the most effective being the anti-DNP fraction. The dose of lgG necessary to achieve $50 \%$ inhibition of proliferation was $75 \mu \mathrm{g}$ for IVIg, $15 \mu \mathrm{g}$ for anti-F(ab') $)_{2}$, and $8 \mu \mathrm{g}$ for anti-DNP fractions.

The secretion of IL-2, IL- $1 \beta$, IL- 4 , IFN- $\gamma$, and TNF- $\alpha$ by $\mathrm{PBMC}$ was reduced in a dose-dependent fashion in the 72-hour supernatants of IVIg containing MLC cultures (Fig. 5). The anti-DNP fraction exhibited a stronger capacity to inhibit the secretion of most cytokines with an intermediate inhibitory values for anti- $F\left(a b^{\prime}\right)_{2}$ fraction. Moreover, the anti-DNP fraction exerted a strong capacity to stimulate IL-1ra secretion, which was not the case for unfractionated IVIg and anti- $\mathrm{F}\left(\mathrm{ab} \mathrm{b}_{2}\right)_{2}$ fraction. To identify IL-1ra-producing cells, we positively selected CD14 ${ }^{+}$PBMC onto specific beads. However, isolated $\mathrm{CD}_{14}{ }^{+}$cells were activated by the selection process and secreted important amounts of IL-1ra in the absence of IgG. We 


\section{A. MALE NOD MICE}

- - Anti-DNP (0.1 mg)

- - - Anti-F(ab')2 (0.1 mg)

$-\diamond-\operatorname{IVlg}(1 \mathrm{mg})$

$\longrightarrow$ Untreated

* Albumin $(1 \mathrm{mg})$

\section{B. FEMALE NOD MICE}

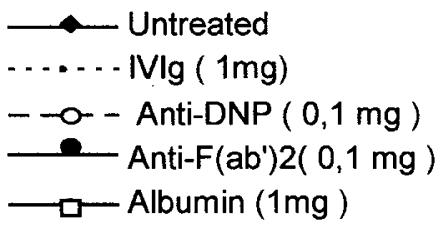

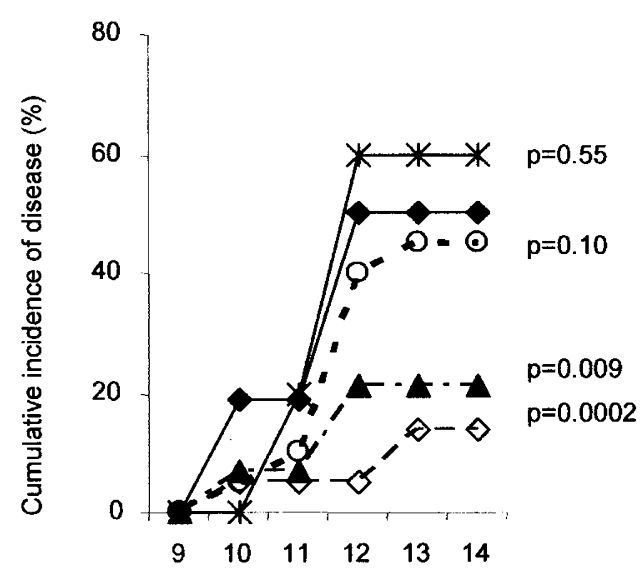

Age of mice in weeks

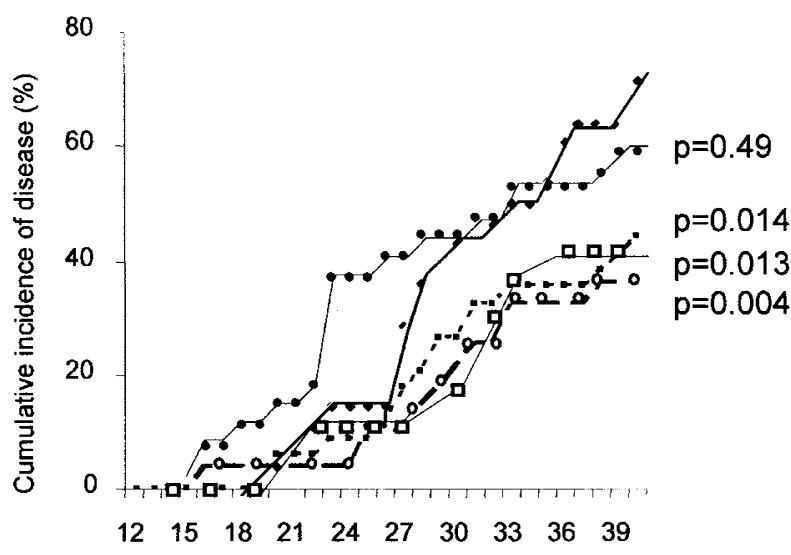

Age of mice in weeks

Figure 3.

Protection against diabetes in nonobese diabetic (NOD) mice is achieved by intravenous immunoglobulin (IVIg) and anti-DNP fraction but not by anti-F(ab') ${ }_{2}$ fraction. Cumulative incidence of diabetes in NOD mice injected ip with IVIg, IVIg fractions, or human serum albumin. Treatment was initiated within 24 hours after birth and continued for 4 weeks. A mouse was considered positive when glycemia exceed $3 \mathrm{~g} / \mathrm{l}$. (A) Diabetes was induced in male NOD mice by the ip injection of $200 \mathrm{mg} / \mathrm{kg}$ of cyclophosphamide at 8 and 10 weeks of age. Untreated mice, $n=16$; mice treated with $1 \mathrm{mg}$ albumin, $n=5 ; 1 \mathrm{mg} \mathrm{IVIg,} n=21 ; 0.1 \mathrm{mg}$ anti-F(ab') ${ }_{2}$ fraction $n=20 ; 0.1 \mathrm{mg}$ anti-DNP fraction, $n=14$. (B) Diabetes developed spontaneously in female NOD mice. Untreated mice, $n=20 ;$ mice treated with $1 \mathrm{mg}$ albumin, $n=17 ; 1 \mathrm{mg} \mathrm{IVIg}, n=27 ; 0.1 \mathrm{mg}$ anti-F(ab') ${ }_{2}$ fraction, $n=27 ; 0.1 \mathrm{mg}$ anti-DNP fraction, $n=28$. Statistical analysis was performed using the logrank chi-square test and compared experimental groups to the untreated group.

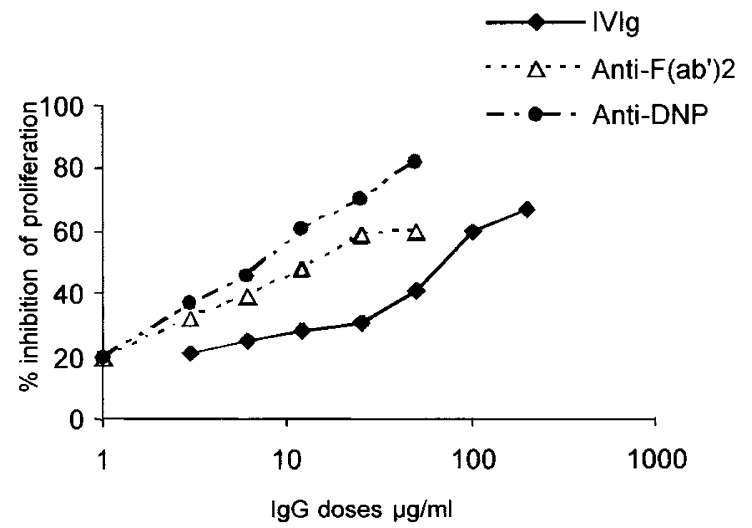

Figure 4.

Anti-dinitrophenyl (DNP) and anti- $F\left(\mathrm{ab}^{\prime}\right)_{2} \lg \mathrm{G}$ fractions inhibited more strongly than intravenous immunoglobulin (IVIg) the lymphocyte proliferation observed during mixed lymphocyte culture. Peripheral blood lymphocyte (PBL) from two unrelated healthy donors were cultured together for 72 hours in the presence of various concentrations of anti-DNP, anti-F(ab') $)_{2}$ fractions, and IVIg; thymidine was added during an additional 6 hours of culture. Radioactivity was measured, and results are presented in percent inhibition of thymidine incorporation as a function of $\mathrm{IgG}$ concentration. Results represented the mean of two to three experiments using different preparations of the fractions.

further isolated $\mathrm{CD}^{+}$and $\mathrm{CD}^{-}$cell populations from PBMC and stimulated them with ConA in the presence of different doses of unfractionated IVIg or anti-DNP fraction. We observed that the $\mathrm{CD}^{-}$but not the $\mathrm{CD}^{+}$ population secreted high amounts of IL-1ra in the presence of the anti-DNP fraction but not in the presence of unfractionated IVIg (Fig. 6). We then cultured the myelomonocytic human cell line THP1 and detected higher amounts of IL-1ra in cell culture supernatants in the presence of 50,25 , and $12 \mu \mathrm{g} / \mathrm{ml}$ $\operatorname{lgG}$ of anti-DNP fraction than in the presence of similar IgG concentrations of anti-F(ab') fraction (Fig. 7). Moreover, unfractionated IVIg did not stimulate IL-1ra production by THP1 cells at similar dosages.

\section{Anticytokine, Anti-Fas, and Anti-CD4 Autoantibodies in IVIg, Anti-DNP, and Anti-F(ab') ${ }_{2}$ Fractions}

The anti-DNP fraction expressed a higher degree of enrichment in anti-CD4 and anti-Fas autoantibodies and in autoantibodies directed toward IL-1 $\beta$, IL-2, IFN- $\gamma$, TNF- $\alpha$, and IL-1ra as compared with IVIg (Table 2). The degree of enrichment in autoantibodies of the anti- $F\left(a b^{\prime}\right)_{2}$ fraction with reference to IVIg was much lower than that of the anti-DNP fraction, with the exception of anti-CD4 autoantibody. In addition, no IL-1 $\beta$, IL-2, IFN- $\gamma$, TNF- $\alpha$, IL-1ra, and transforming growth factor- $\beta$ were detected in IVIg and fractions by ELISA assays using anticytokine antibodies-coated plates (data not shown). 

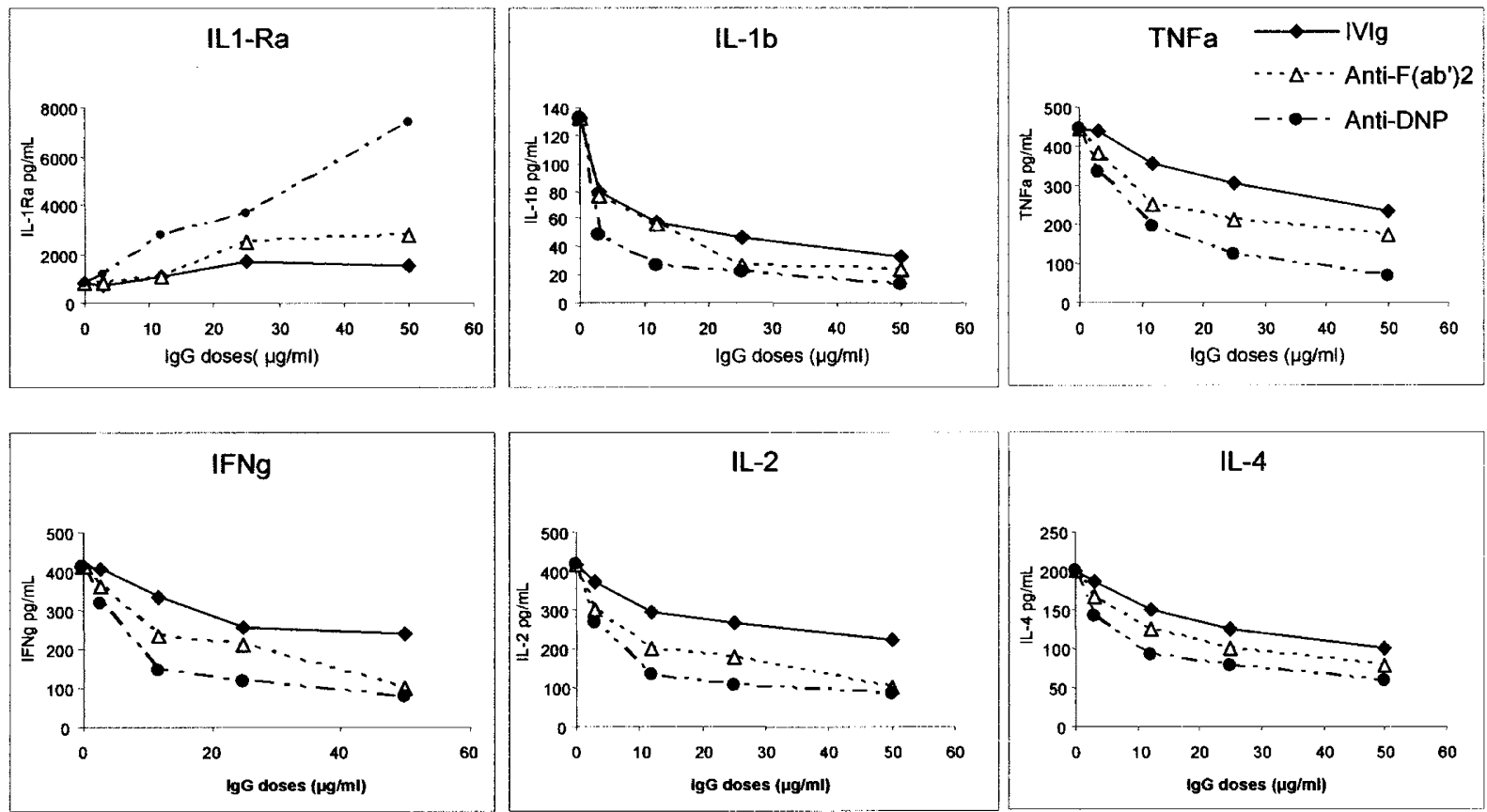

Figure 5.

Anti-dinitrophenyl (DNP) and anti-F(ab') ${ }_{2}$ fractions inhibited the secretion of IL- $1 \beta$, TNF- $\alpha$, IFN- $\gamma$, IL-4, and IL-2 more efficiently than intravenous immunoglobulin (IVIg). Anti-DNP fraction but not anti-F(ab') fraction stimulated the production of IL-1 receptor antagonist. Cytokine levels were assayed by ELISA in the 72-hour supernatants of mixed lymphocyte culture performed in the presence of various concentrations of IgG from IVIg and fractions. The results are expressed as the mean of two to three experiments using different preparations of the fractions.

\section{$\mathrm{IL}-1$ ra production by human $\mathrm{PBL}$}

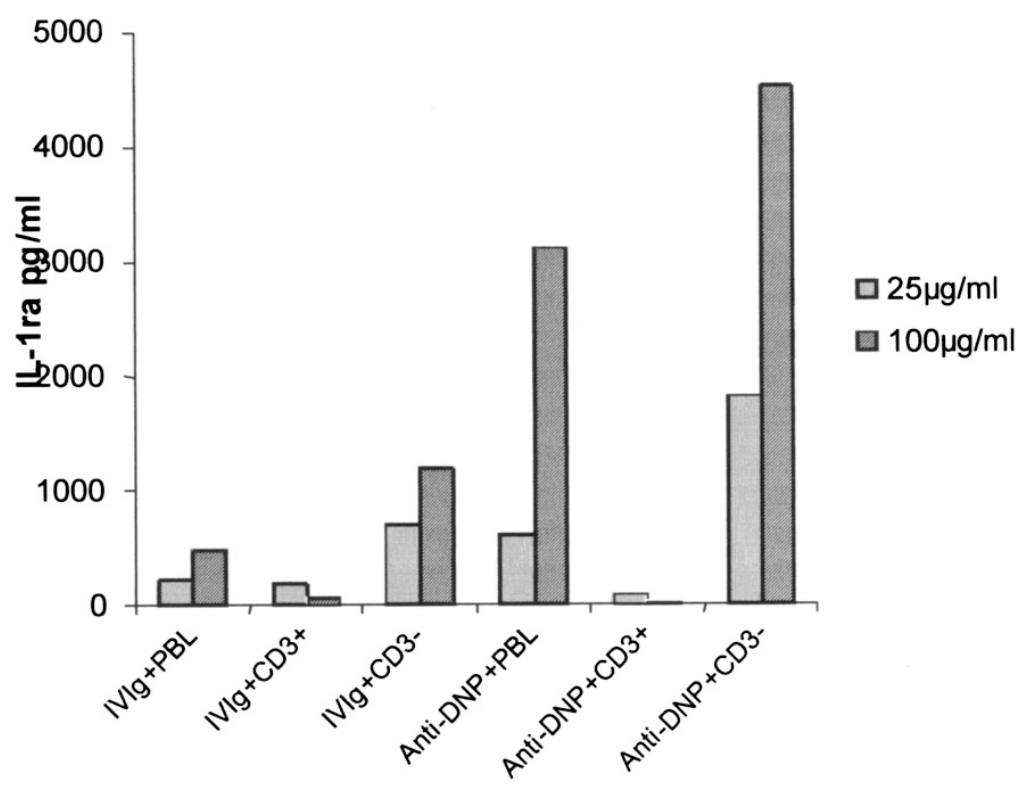

in vitro treatment

Figure 6.

Anti-dinitrophenyl (DNP) fraction but not IVIg increased in a dose-dependent fashion the secretion of IL-1 receptor antagonist (IL-1ra) by T-cell depleted peripheral blood mononuclear cells (PBMCs). IL-1ra level was assayed by ELISA in the 72-hour supernatants of ConA-stimulated PBMC in the presence of various concentrations of IgG from IVIg and anti-DNP fraction. A typical experiment is presented. 


\section{IL-1ra production by THP1 cells}

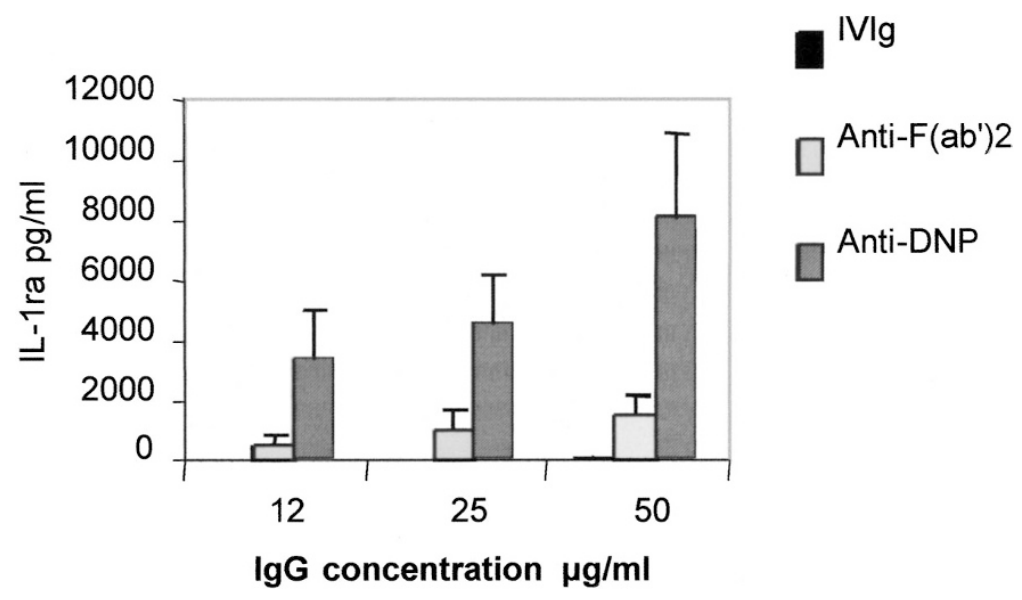

Figure 7.

Anti-DNP fraction but not anti-F(ab') ${ }_{2}$ fraction or intravenous immunoglobulin (IVIg) increased in a dose-dependent fashion the secretion of IL-1 receptor antagonist (IL-1ra) by THP1 cell line. IL-1ra level was assayed by ELISA in the 72-hour supernatants of THP1 cells in the presence of various concentrations of IgG from IVIg and fractions. The results are expressed as the mean of two to three experiments using different preparations of the fractions.

Table 2. Presence of Autoantibodies Against Immunoregulatory Molecules in Affinity Purified Anti- $\mathrm{F}\left(\mathrm{ab}^{\prime}\right)_{2}$ and Anti-DNP-Lysine Enriched Fractions of IVIg

\begin{tabular}{|c|c|c|}
\hline \multirow{2}{*}{$\begin{array}{l}\text { Immune } \\
\text { molecules }\end{array}$} & \multicolumn{2}{|c|}{$\begin{array}{c}\text { Mean }^{a} \pm \text { SD level of enrichment in } \\
\text { autoantibodies in the fractions compared } \\
\text { to IVIg }\end{array}$} \\
\hline & Anti-F(ab' $)_{2}$ fraction & Anti-DNP fraction \\
\hline Fas & $6.0 \pm 1.0$ & $31.0 \pm 9.0$ \\
\hline CD4 & $14.2 \pm 5.5$ & $16.5 \pm 1.9$ \\
\hline IL-2 & $1.4 \pm 1.2$ & $23.3 \pm 2.7$ \\
\hline TNF- $\alpha$ & $1.0 \pm 0.9$ & $26.0 \pm 5.0$ \\
\hline $\mathrm{IL}-1-\beta$ & $1.6 \pm 1.1$ & $37.2 \pm 9.2$ \\
\hline INF- $\gamma$ & $2.9 \pm 0.8$ & $39.6 \pm 6.4$ \\
\hline IL-1ra & $1.1 \pm 1.0$ & $16.5 \pm 3.5$ \\
\hline
\end{tabular}

DNP, dinitrophenyl; IVIg, intravenous immunoglobulin.

${ }^{a}$ Mean of two to three different fractions.

\section{Discussion}

Our results indicate that a very small fraction of IVIg interacting with DNP but not with $F(a b)_{2}$ fragments of IVIg expressed an increased ability to bind to selfantigens and not to the TT.

The anti- $F\left(a b{ }^{\prime}\right)_{2}$ fraction eluted in the presence of $\mathrm{NaCl}$ and containing a low percentage of polymers was strongly enriched in antibodies recognizing $\mathrm{F}(\mathrm{ab})_{2}$ fragments but only weakly reactive with selfantigens and the DNP hapten. Because intact IVIg was used to affinity purify the anti-F(ab') fraction, we cannot exclude the possibility that some of the antibodies in this fraction could recognize Fc fragments of IgG; however, very few anti-Fc $\gamma$ antibodies were detected in IVIg, and we think that the majority of retained IgG were anti-F(ab') ${ }_{2}$ antibodies.

Conversely, the anti-DNP fraction did not bind to $\mathrm{F}(\mathrm{ab})_{2}$ fragments of IVIg but was highly enriched in
IgG reactive with self-antigens, ie, in natural autoantibodies(Berneman et al, 1992; Dighiero et al, 1983). It was previously demonstrated that the IVIg fraction that binds to the DNP hapten is enriched in polyreactive autoantibodies (Berneman et al, 1993) and that DNP competes with autoantigens for the binding of specific autoantibodies (Druet et al, 1994). The binding of antibodies in this fraction to DNP was inhibited in the presence of actin, myosin, and tubulin, indicating that these autoantigens share the same binding site on IgG molecules as the DNP hapten. In addition, because the eluate of a DNP-Affiprep-NHS column loaded with $F\left(a b^{\prime}\right)_{2}$ fragments of IVIg was strongly enriched in anti-DNP activity (data not shown), we believe that the recognition of DNP may be $F(a b)_{2}$ dependent.

The percentage of anti-DNP IgG retained on the NHS-Affiprep column is very small $(0.13 \%)$ in comparison to the previously reported $30 \%$ of IVIg binding to DNP coupled to Sepharose (Rossi et al, 1991). However, Farah observed that only $0.4 \%$ of $\operatorname{lgG}$ was retained when an amino-ethyl cellulose gel coupled to DNP was loaded with IVIg (Farah, 1973). The differences in adsorption and elution conditions and in the immunoadsorbent used could help explain the discrepancy between our results and those previously reported in the literature (Berneman et al, 1993; Farah, 1973).

We have observed that the two antibody fractions purified from IVIg exert mutually exclusive antibody activities: the anti-DNP fraction bound to self-antigens but not to $F\left(a b{ }^{\prime}\right)_{2}$ fragments of IVIg and the anti-F(ab') fraction interacted weakly to self-antigens. These results differed from those obtained by Dietrich et al (1993), who reported that a fraction of IVIg obtained by affinity purification onto Sepharose-bound $F(a b)_{2}$ fragments of IVIg contained antibodies connected through $V$ regions and also expressed a higher degree of autoreactivity than unfractionated IVIg. Two expla- 
nations can be proposed to account for this discrepancy. Firstly, in our hands Sepharose gel nonspecifically adsorbed self-reactive IgG, whereas Affigel and Affiprep gels exerted negligible nonspecific IgG adsorption (data not shown), and we speculate that the autoantibody activity of this anti-F(ab') $)_{2}$-connected fraction may result at least in part from Sepharose nonspecific binding of IgG. Secondly, because we and others have observed that the amount of polymers increased as the $\mathrm{pH}$ lowered and that the degree of polyreactivity was correlated with the amount of polymers (MacMahon and O'Kennedy, 2000), we did not use glycine- $\mathrm{HCl}$ pH 2.8 alone as Dietrich et al (1993) did, but we added $\mathrm{NaCl}$ during acid elution of IVIgcoupled Affigel. This process prevented the formation of polymers and considerably reduced the polyreactivity of the anti-F(ab') ${ }_{2}$ fraction.

As previously shown, we confirmed that IVIg prevented the occurrence of CIA (Ulmansky and Napastek, 1995) and EAE (Achiron et al, 2000) in rats and diabetes mellitus in NOD mice (Andersson et al, 1991; Fosgren et al, 1991). Before injecting fractions into animals, we first compared iv and ip routes of administration of IVIg in CIA and observed for both routes the same strong protective effect at $500 \mathrm{mg} / \mathrm{kg}$. Moreover, by measuring serum IgG concentrations after ip and iv IVIg infusion, we obtained similar results at 6 hours, whereas at 3 hours higher IgG concentration was measured when IVIg were administered by iv route. These results validate the ip route used in the CIA model. In the EAE model, ip administration of IVIg had no protective effect, suggesting that IgG did not efficiently cross the blood-brain barrier. Consequently, IgG was administrated intrathecally.

Data indicated that the anti-DNP fraction but not the anti- $\mathrm{F}(\mathrm{ab})_{2}$ fraction protected against inflammation associated with $\mathrm{CIA}$ in rats and reduced the occurrence of diabetes in NOD mice at concentrations 10-fold lower than unfractionated IVIg. The anti-DNP fraction also reduced more effectively EAE symptoms than unfractionated IVIg. The mechanisms that have been proposed to explain the beneficial effect of IVIg in autoimmune and systemic inflammatory diseases include IVIg interactions with Fc receptors, complement proteins and cell-surface molecules, neutralization of circulating autoantibodies, and modulation of cytokine production and cell proliferation (Kazatchkine et al, 2001; Yu and Lennon, 1999).

Two Fc-dependent mechanisms have recently been described that contribute to the therapeutic effect of IVIg in autoantibody-mediated diseases, ie, increased IgG catabolism (Yu and Lennon, 1999) and induction of the inhibitory receptor Fc- $\gamma$ RIIB expression on macrophages surface (Samuelsson et al, 2001). In our models, we observed that low amounts $(5 \mathrm{mg} / \mathrm{kg}$ in $\mathrm{CIA}, 25 \mathrm{mg} / \mathrm{kg}$ in $\mathrm{EAE}$, and $0.1 \mathrm{mg}$ in newborn NOD mice) of natural autoantibody-enriched fraction protected from the development of autoimmune experimental diseases, whereas similar doses of IVIg did not. Therefore, we do not think that these results can only be explained by an effect through $\mathrm{Fc}-\gamma$ receptors and stress the role of variable regions of anti-DNP IgG as an explanation to biological effects observed in vivo and in vitro. Conversely, we postulated that the antiidiotype fraction failed to protect better than IVIg because our experimental models of autoimmune diseases were T-cell dependent.

Many authors have demonstrated that IVIg upregulate IL-1ra (Andersson et al, 1994; Arend and Leung, 1994; Ruiz de Souza et al, 1995) and downregulate IL-1 synthesis and release (Okitsu-Negishi et al, 1994) in vitro and in vivo, thereby explaining their major anti-inflammatory effect in certain autoimmune and systemic inflammatory diseases. Our data provide evidence that the anti-DNP fraction, and to a lesser degree the anti-F(ab') ${ }_{2}$ fraction, inhibited lymphocyte proliferation and secretion of IL-2, IL- $1 \beta$, IL-4, IFN- $\gamma$, and TNF- $\alpha$ during MLC in a greater proportion than IVIg. Although the data on Th1 lymphokines in the literature are concordant with the down-regulation of IL-2 and IFN- $\gamma$ by IVIg in vitro, conflicting results have been reported concerning IL-4 and TNF- $\alpha$. The main difference between anti-DNP and anti- $F\left(a b^{\prime}\right)_{2}$ fractions was the unique ability of the anti-DNP fraction to stimulate the secretion of high amounts of IL-1ra. These data were confirmed in experiments showing that the THP1 myelomonocytic cell line produces a high amount of IL-1ra in the presence of the anti-DNP fraction but not in the presence of the anti-F(ab') fraction or total IVIg. IL-1ra is a strong natural antiinflammatory molecule that is produced by monocytes and binds to the IL-1 $\beta$ receptor. Furthermore, we found that the amounts of naturally occurring autoantibodies recognizing various cell-surface molecules and cytokines already described to be present in IVIg (Kazatchkine and Kaveri, 2001; Larroche et al, 2002) were increased in the anti-DNP fraction. Thus, the combination of an inhibition in proinflammatory cytokine secretion such as IL- $1 \beta$, IFN- $\gamma$, and TNF- $\alpha$; a stimulation of IL-1ra secretion; and the presence of natural anticytokine antibodies (Abe et al, 1994) could explain the therapeutic effect of the anti-DNP fraction compared with IVIg in experimental autoimmune diseases in which inflammatory reactions are part of the disease process. However, the detailed mechanism by which IgG presents in the anti-DNP fraction modulate cytokine production remains to be determined.

The active fraction in IVIg corresponds to a very small percentage of $\mathrm{IgG}$ and probably is not representative of the total immunomodulatory effect of IVIg. Natural polyreactive autoantibodies may play a role in the protective effect of IVIg and could potentially represent a new generation of IVIg treatments with the theoretical benefit of inducing similar responses with much lower doses of lgG.

\section{Materials and Methods}

\section{Animals}

All animals used were bred and maintained in our animal facility. Two- to three-month-old male Dark Agouti and female Lewis rats (mean weight, 180 to $200 \mathrm{~g}$ ) were purchased from Janvier (Le Genest St Isle, 
France). NOD (Ltd) mice were purchased from Iffa Credo (L'Arbresle, France).

\section{$\lg G$}

IVIg (Tegeline) was prepared by LFB (Les Ulis, France) as previously described (Malgras et al, 1970) from a pool of plasma from more than 5000 healthy blood donors.

\section{Affinity Chromatography}

IVIg were coupled to Affigel-NHS (Bio-Rad, Hercules, California) immunoadsorbent at a concentration of 5 $\mathrm{mg} / \mathrm{ml}$ of gel. Two grams of IVlg in PBS were loaded and circulated on a $2-\mathrm{L}$ column for 4 hours at $22^{\circ} \mathrm{C}$. Retained Ig were eluted with glycine- $\mathrm{HCl}$ at various $\mathrm{pH}$ values (2.8 to 3.5 ) with or without $0.15 \mathrm{M} \mathrm{NaCl}$ and immediately brought to $\mathrm{pH} 4$ with $\mathrm{NaOH}$. This fraction is referred to as the "anti- $F(a b ')_{2}$ fraction."

DNP-lysine (Sigma, St Quentin Falavier, France) was coupled to Affiprep-NHS (Bio-Rad) at a concentration of $5 \mathrm{mg} / \mathrm{ml}$ of gel. Six grams of IVlg were loaded and circulated on a 2- L column for 4 hours at $22^{\circ} \mathrm{C}$. Retained $\mathrm{lg}$ were eluted with $2 \mathrm{M} \mathrm{Nal} \mathrm{pH} 7.0$ and further desalted on a G25 Sephadex column. This fraction is referred to as the "anti-DNP fraction."

The eluates were concentrated on 50-kd membranes (Macrosep, Filtron; Pall Life Sciences, Ann Harbor, Michigan) and frozen at $-80^{\circ} \mathrm{C}$ until use. The percentage of monomers, dimers, polymers, and fragments were determined by high pressure liquid chromatography gel filtration on a G 3000 TSK column (Merk, Darmstad, Germany).

\section{Detection of Antibody Reactivities with Self- and Nonself-Antigens by ELISA and Western Blotting}

The eluates were assessed by ELISA for antibody reactivity against DNP-albumin (Sigma), $F\left(a b{ }^{\prime}\right)_{2}$ fragments of IVIg (Tegeline, LFB), calf actin (Sigma), calf myosin (Sigma), guinea pig MBP (Sigma), pig tubulin (Institut Pasteur, Paris, France), and TT (Pasteur Merieux, Lyon, France). Ninety-six-well ELISA plates were coated overnight at $37^{\circ} \mathrm{C}$ with $\left.\mathrm{F}(\mathrm{ab})_{2}\right)_{2}$ or 1 hour at $37^{\circ} \mathrm{C}$ and subsequently overnight at $4^{\circ} \mathrm{C}$ with all other antigens. The plates were saturated with $1 \%$ milk (for $\mathrm{F}\left(\mathrm{ab}^{\prime}\right)_{2}$ ) or $1 \%$ BSA (for other antigens) and incubated for 1 hour at $22^{\circ} \mathrm{C}$. Increasing amounts of IVlg and of the various eluates diluted in PBS-gelatin were added to the wells and incubated for 2 hours at $37^{\circ} \mathrm{C}$ or $22^{\circ} \mathrm{C}$. After extensive washing, plates were incubated with peroxydase-labeled $\gamma$-chain specific goat antihuman $\operatorname{lgG}$ antibody and then revealed with o-phenylenediamine. The enzyme reaction was stopped after 5 minutes and optical density measured at $490 \mathrm{~nm}$ (Labsystem, Cergy Pontoise, France). The results were expressed as a ratio of enrichment as compared with unfractionated IVIg.

IgG reactivity of unfractionated IVIg and the antiDNP and anti- $F\left(a b^{\prime}\right)_{2}$ fractions with liver and muscle extracts were analyzed using a quantitative immuno- blotting technique as described by Mouthon et al (1995).

\section{MLC, THP1 Culture, and Cytokine Secretion}

Peripheral blood was collected from two healthy donors and mononuclear cells (PBMC) were separated on ficoll density gradient centrifugation. Bidirectional MLCs were established between donor A (1.5 $10^{5}$ cells/well) and donor B (1.5 $10^{5}$ cells/well) in a total volume of $200 \mu \mathrm{L}$ in 96-well flat-bottom tissue culture plates. Cells were cultured at $37^{\circ} \mathrm{C}$ in $5 \% \mathrm{CO}_{2}$ in RPMI 1640 supplemented with $1 \mathrm{mmol} / \mathrm{L}$ L-glutamine and $10 \%$ FCS in the presence of serially diluted IgG from IVIg and fractions, and supernatants were collected after 72 hours for cytokine measurement. For proliferation assay, $200 \mu \mathrm{L}$ of fresh medium was added, and cultures were pulsed with $1 \mu \mathrm{Ci}$ of ${ }^{3} \mathrm{H}-$ thymidine for an additional 6 hours. Cells were harvested, and ${ }^{3} \mathrm{H}$-thymidine incorporation was determined in a beta counter (Kontron, Plaisir, France). Purification of $\mathrm{CD}^{+}, \mathrm{CD}^{-}$, or $\mathrm{CD}_{1} 4^{+}$cell populations from PBMC was performed using microbeads and magnetic column selection (MACS, Miltenyi Biotech, Germany).

The myelomonocytic cell line THP1 (ATCC, TIB 202) was cultured in 1640 RPMI medium supplemented with $10 \%$ FCS at the concentration of $10^{5}$ cells per $\mathrm{ml}$ in $9-\mathrm{cm}^{2}$ culture Petri dishes in the presence of serially diluted IgG from IVIg and fractions. After 72 hours of culture, cells were numbered and supernatants collected for IL-1ra measurement.

\section{Cytokine ELISA Assays}

IL-1ra, IL- $1 \beta$, IL-2, IFN- $\gamma$, IL-4, and TNF- $\alpha$ were quantitated using ELISA kits (R\&D Systems, Abingdon, United Kingdom) according to the manufacturer's instructions. The amount of cytokines was expressed in $\mathrm{pg} / \mathrm{ml}$, and the minimum detectable concentrations were $150 \mathrm{pg} / \mathrm{mL}$ for $\mathrm{IL}-1 \mathrm{ra}, 5 \mathrm{pg} / \mathrm{mL}$ for $\mathrm{IL}-1 \beta$, and 20 $\mathrm{pg} / \mathrm{mL}$ for IL-2, IL-4, IFN- $\gamma$, and TNF- $\alpha$. MLC culture supernatants were harvested and tested undiluted to determine cytokine concentration. THP1 culture supernatants were serially diluted and tested to determine IL-1ra concentration.

\section{Detection of Anticytokine, Anti-Fas and Anti-CD4 Neutralizing Antibodies}

Serially diluted IVIg and anti-DNP and anti-F(ab') ${ }_{2}$ fractions were incubated for 1 hour at $37^{\circ} \mathrm{C}$ in culture plates coated with recombinant IL-1ra $(100 \mathrm{ng} / \mathrm{ml})$, IL-1 $\beta(10 \mathrm{ng} / \mathrm{ml})$, IL-2 $(20 \mathrm{ng} / \mathrm{ml}), \mathrm{IFN}-\gamma(20 \mathrm{ng} / \mathrm{ml})$, TNF- $\alpha$ (20 ng/ml) (R\&D Systems), recombinant human Fas $(1 \mu \mathrm{g} / \mathrm{ml})$ (R\&D Systems), and CD4 (100 ng/ml of purified protein) (a gift from Dr. Klatzman). The presence of antibodies against these molecules was revealed in ELISA by peroxydase-labeled rabbit antihuman IgG as described above. Results were presented as the level of enrichment in autoantibodies in antiDNP and anti- $F\left(a b^{\prime}\right)_{2}$ fractions compared with unfractionated IVIg. 


\section{Collagen-Induced Arthritis}

Type II bovine collagen (Morwell, Zurich, Switzerland) was dissolved vol/vol in $0.1 \mathrm{M}$ acetic acid and emulsified in incomplete Freund adjuvant (DIFCO, Detroit, Michigan). One ml emulsion containing 250 to $350 \mu \mathrm{g}$ collagen was injected intradermally at the base of the tail and on the back above each leg. Each experimental group included six to eight rats, and experiments were performed twice.

The rats were examined daily for inflammatory signs such as erythema and swelling (Ulmansky and Naparstek, 1995). The ankle, tarsus, and metatarsus joints were scored as follows: $0=$ unaffected, $1=$ joint erythema, 2 = localized or moderate joint swelling, 3 $=$ serious swelling and edematous aspect, and $4=$ deformity of the joints. The total score for each animal was calculated as an arthritis index (maximum 48). The IVIg and affinity purified fractions were injected ip at $200,50,5$, or $0.5 \mathrm{mg} / \mathrm{kg}$ for 4 days starting the day of immunization. HSA was used as a control.

\section{Experimental Autoimmune Encephalomyelitis}

One $\mu \mathrm{g}$ of MBP (Sigma) was emulsified in complete Freund adjuvant plus mycobacterium at the dose of $400 \mu \mathrm{g}$ per animal (DIFCO) and injected in each hind footpad of female Lewis rats. The following validated clinical severity scale was used: $0=$ normal, $1=$ decreased tail tone, 2 = tail paralysis, $3=$ paraparesis, $4=$ paraplegia, and $5=$ moribund (Achiron et al, 2000).

The IVIg and anti-DNP fraction were administered at different dosages from Day 0 to Day 8 either by ip or intrathecal route.

\section{Insulin-Dependent Diabetes Mellitus in NOD Mice}

Newborn NOD mice were injected three times a week ip with $1 \mathrm{mg}$ unfractionated IVlg or $0.1 \mathrm{mg}$ of the anti-DNP or anti- $\left(a b^{\prime}\right)_{2}$ fraction and $1 \mathrm{mg} \mathrm{HSA}$ as a control. The treatment was initiated within 24 hours after birth and continued for 4 weeks.

Diabetes mellitus that developed spontaneously in $60 \%$ of female NOD mice was monitored from 8 to 40 weeks of age by measuring blood glucose concentration using the glucometer Eprit (Bayer Diagnostics, Munich, Germany) colorimetric assay. Animals were considered diabetic when blood glucose concentration exceeded $3 \mathrm{~g} / \mathrm{l}$ for 2 weeks consecutively (Andersson et al, 1991).

Because only $20 \%$ of male NOD mice spontaneously developed insulin-dependent diabetes mellitus, the disease was accelerated by injection of CYC given at the dose of $200 \mathrm{mg} / \mathrm{kg}$ ip twice, at 8 and 10 weeks of age (Yasunami and Bach, 1988). Blood glucose level was measured after retro-orbital bleeding before the second CYC injection and every week thereafter until 15 weeks of age.

\section{Acknowledgements}

We thank S. Avrameas, W.H. Fridman, and M.D. Kazatchkine for their advice and active participation in discussions. Animal experiments were done in our animal facilities (LFB, Les Ulis, accreditation No. 91639) by G. Clarisse (No. 03697) and M. BruleyRosset (No. 91-9) according to European Council directives No. 86/609 concerning the protection of animals used for experimental and research purposes and to current laboratory procedures.

\section{References}

Abe Y, Horiuchi A, Miyake M, and Kimura S (1994). Anticytokine nature of human immunoglobulin: One possible mechanism of the clinical effect of intravenous therapy. Immunol Rev 139:5-19.

Achiron A, Mor F, Margalit R, Cohen IR, Lider O, and Miron S (2000). Suppression of experimental autoimmune encephalomyelitis by intravenous administered polyclonal immunoglobulins. J Autoimmunity 15:323-329.

Andersson A, Forsgren S, Söderström A, and Holmberg D (1991). Monoclonal, natural antibodies prevent development of diabetes in non-obese diabetic (NOD) mouse. J Autoimmunity 4:733-742.

Andersson U, Bjork L, Skansen-Saphir U, and Andersson J (1994). Pooled human IgG modulates cytokine production in lymphocytes and monocytes. Immunol Rev 139:21-42.

Arend $P$ and Leung DY (1994). IgG induction of IL-1 receptor antagonist production by human monocytes. Immunol Rev 139:71-78

Berneman A, Guilbert B, Eschrich S, and Avrameas S (1993). IgG auto- and polyreactivites of normal human sera. Mol Immunol 30:1499-1510.

Berneman A, Ternynck T, and Avrameas S (1992). Natural mouse IgG reacts with self antigens including molecules involved in the immune response. Eur J Immunol 22:625631.

Coutinho A, Kazatchkine MD, and Avrameas S (1995). Natural autoantibodies. Curr Opin Immunol 7:812-818.

Dalakas MC (1997). Intravenous immune globulin therapy for neurologic diseases. Ann Intern Med 126:721-730.

Dietrich G, Kaveri SV, and Kazatchkine MD (1993). A V region-connected autoreactive subfraction of normal human serum immunoglobulin G. Eur J Immunol 22:1701-1706.

Dighiero G, Guilber B, Fermand JP, Lymberi P, Danon P, and Avrameas S (1983). Thirty-six human monoclonal immunoglobulins with antibody activity against cytoskeleton proteins, thyroglobulin and native DNA: Immunologic studies and clinical correlation. Blood 62:264-270.

Druet E, Guery JC, Ayed K, Guilbert B, Avrameas S, and Druet $P(1994)$. Characteristics of polyreactive and monospecific IgG anti-laminin autoantibodies in the rat mercury model. Immunology 83:489-494.

Dwyer JM (1992). Manipulating the immune system with immune globulin. N Engl J Med 326:107-116.

Farah FS (1973). Natural antibodies specific to the 2, 4-dinitrophenyl group. Immunology 25:217-226.

Fosgren S, Anderson A, Hillorn V, Soderstrom A, and Holmberg D (1991). Immunoglobulin-mediated prevention of autoimmune diabetes in non-obese diabetic (NOD) mouse. Scand J Immunol 34:445-451. 
Hayakawa K, Asano M, Shinton SA, Gui M, Allman D, Stewart CL, Silver J, and Hardy RR (1999). Positive selection of natural autoreactive B cells. Science 285:113-116.

Kaveri SV, Wang H, Rowen D, Kazatchkine MD, and Kolher $\mathrm{H}$ (1993). Monoclonal anti-idiotypic antibodies against human anti-thyroglobulin autoantibodies recognize idiotopes shared by disease-associated and natural anti-thyroglobulin autoantibodies. Clin Immunol Immunopathol 69:333-340.

Kazatchkine MD, Dietrich G, Hurez V, Ronda N, Bellon B, Rossi F, and Kaveri SV (1994). V region-mediated selection of autoreactive repertoires by Intravenous Immunoglobulin (IVIg). Immunol Rev 139:79-107.

Kazatchkine MD and Kaveri SV (2001). Immunomodulation of autoimmune and inflammatory diseases with intravenous immunoglobulin G (IVlg). N Engl J Med 345:747-755.

Lacroix-Desmazes S, Kaveri SV, Mouthon L, Ayouba A, Malanchere E, Coutinho A, and Kazatchkine MD (1998). Self-reactive antibodies (natural autoantibodies) in healthy individuals. J Immunol Methods 216:117-137.

Larroche C, Chanseaud Y, Garcia de la Pena, Lefebvre P, and Mouthon $L$ (2002). Mechanisms of intravenous immunoglobulin action in the treatment of autoimmune disorders. BioDrugs 16:47-55.

MacMahon MJ and O'Kennedy R (2000). Polyreactivity as an acquired artefact, rather than a physiologic property, of antibodies: Evidence that monoreactive antibodies may gain the ability to bind to multiple antigens after exposure to low pH. J Immunol Methods 241:1-10.

Malgras J, Hauptmann G, Zorn JJ, and Waitz R (1970). Mesure de l'activité anti-complémentaire des préparations de gamma-globulines injectables par voie intra-veineuse. Revue Française de Transplantation 13:173-179.

Marchalonis JJ, Kaymaz H, Schluter SF, and Yocum DE (1993). Human autoantibodies to a synthetic putative T cell receptor beta-chain regulatory idiotype: Expression in autoimmunity and aging. Exp Clin Immunogenet 10:1-15.

Mouthon L, Haury M, Lacroix-Desmazes S, Barreau C, Coutinho A, and Kazatchkine MD (1995). Analysis of the normal human IgG antibody repertoire. J Immunol 154:57695778.
Okitsu-Negishi S, Furusawa S, Kawa Y, Hashira S, Ito S, Hiruma F, Mizoguchi M, Yoshino K, and Abe T (1994). Suppressive effect of intravenous immunoglobulins on the activity of interleukin-1. Immunol Res 13:49-51.

Rhoades CJ, Williams MA, Kelsey SM, and Newland AC (2000). Monocyte-macrophage system as target for immunomodulation by intravenous immunoglobulin. Blood Rev $14: 14-15$

Rossi F, Jayne DR, Lockwood CM, and Kazatchkine MD (1991). Anti-idiotypes against anti-neutrophil cytoplasmic antigen autoantibodies in normal human polyspecific IgG for therapeutic use and in the remission sera of patients with systemic vasculitis. Clin Exp Immunol 83:298-303.

Ruiz de Souza V, Carreno MP, Kaveri SV, Ledur A, Sadeghi $\mathrm{H}$, Cavaillon JM, Kazatchkine MD, and Haeffner-Cavaillon N (1995). Selective induction of IL-1ra and IL-8 in human monocytes by normal polyspecific immunoglobulin $\mathrm{G}$ for therapeutic use (IVlg). Eur J Immunol 25:1267-1273.

Samuelsson A, Towers TL, and Ravetch JV (2001). Antiinflammatory activity of IVIg mediated through the inhibitory Fc receptor. Science 291:484-486.

Seigneurin JM, Guilbert B, Bourgeat MJ, and Avrameas S (1988). Polyspecific natural antibodies and autoantibodies secreted by human lymphocytes immortalized with EpsteinBarr virus. Blood 71:581-585.

Ulmansky R and Naparstek $Y$ (1995). Immunoglobulins from rats that are resistant to adjuvant arthritis suppress the disease in arthritis-susceptible rats. Eur J Immunol 25:952957.

van Schaik IN, Lundkvist I, Vermeulen M, and Brand A (1992). Polyvalent immunoglobulin for intravenous use interferes with cell proliferation in vitro. J Clin Immunol 12:325-334.

Yasunami R and Bach JF (1988). Anti-suppressor effect of cyclophosphamide on the development of spontaneous diabetes in NOD mice. Eur J Immunol 18:481-484.

Yu Z and Lennon VA (1999). Mechanism if intravenous immune globulin therapy in antibody-mediated autoimmune disease. N Engl J Med 340:227-228. 